\title{
Paula Findlen (dir.), Early Modern Things Objects and their Histories, 1500-1800
}

London and New York, Routledge, 2012

\section{Audrey Millet}

\section{(2) OpenEdition}

\section{Journals}

\section{Édition électronique}

URL : http://journals.openedition.org/artefact/555

DOI : $10.4000 /$ artefact.555

ISSN : 2606-9245

Éditeur :

Association Artefact. Techniques histoire et sciences humaines, Presses universitaires du Midi

Édition imprimée

Date de publication : 1 octobre 2016

Pagination : 421-423

ISBN : 978-2-7535-5174-9

ISSN : 2273-0753

\section{Référence électronique}

Audrey Millet, «Paula Findlen (dir.), Early Modern Things Objects and their Histories, 1500-1800», Artefact [En ligne], 4 | 2016, mis en ligne le 07 juillet 2017, consulté le 24 septembre 2020. URL : http:// journals.openedition.org/artefact/555; DOI : https://doi.org/10.4000/artefact.555

Ce document a été généré automatiquement le 24 septembre 2020.

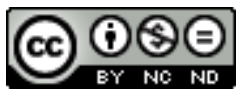

Artefact, Techniques, histoire et sciences humaines est mise à disposition selon les termes de la Licence Creative Commons Attribution - Pas d'Utilisation Commerciale - Pas de Modification 4.0 International. 


\section{Paula Findlen (dir.), Early Modern Things Objects and their Histories, 1500-1800}

London and New York, Routledge, 2012

Audrey Millet

\section{RÉFÉRENCE}

Paula Findlen (dir.), Early Modern Things Objects and their Histories, 1500-1800, London and New York, Routledge, 2012, 392 p.

1 Les objets ont une histoire. C'est ce que nous dit le volume collectif édité par Paula Findlen. En six parties, les auteurs donnent la parole aux «choses ». Le terme employé par tout un chacun pourrait sembler, au premier abord, relativement simple, creux et vide. Pourtant, les diverses approches de l'ouvrage, qualitativement égales, permettent de discuter avec des morceaux de culture matérielle, du ginseng à l'horloge, en passant par des oiseaux. Loin d'être immobiles, ces histoires insistent sur l'évolution constante des choses entre 1500 et 1800 . L'intérêt est évident : nous croyons connaître les objets qui nous entourent. Néanmoins, cette familiarité est un leurre. Les choses doivent être comprises, non pas selon un mode contemplatif, mais à partir de l'expérience. Dès l'introduction, Paula Findlen montre brillamment qu'un tambour a de multiples vies (p. 6). Il faut saisir son corps, sa construction, les divers essais des fabricants pour parvenir à un son clair, le jeu de baguettes du musicien et les choix réalisés dans une visée esthétique. Entendons-nous le tambour? Oui, mais surtout nous en entendons plusieurs. En effet, tout au long de l'ouvrage l'accent est mis sur la variété temporelle et culturelle des objets inscrits dans une géographie large prenant en compte aussi bien un vêtement de l'empire ottoman qu'une nature morte du siècle d'or hollandais. La diversité des objets examinés entraîne des croisements de récits, des comparaisons, des discussions mondiales, transnationales, interculturelles. Au final, les objets parlent au 
lecteur et discutent aussi entre eux. Ils leur apprennent la vie sociale et quotidienne, tout comme les envies du consommateur et les ambitions du fabricant de l'époque. La croissance de la consommation, de la circulation et de l'utilisation des objets, tendance mondiale, forme le carrefour des discussions entre les produits modernes.

2 Selon Findlen, l'ouvrage n'est pas destiné à être un guide méthodologique. Il présente des échantillons historiques visant à écrire des histoires à partir des objets ou l'histoire des objets. Néanmoins, les auteurs nous apprennent à regarder, comprendre, déconstruire, reconstruire et mettre en valeur les mille et une vies des produits. Il s'agit bien d'un exemple méthodologique à suivre. Chaque auteur oriente son analyse selon une perspective propre: économique, culturelle, sociale, technique, ou encore médicale. Les sources mobilisées par les auteurs sont particulièrement diversifiées. Pour comprendre la représentation des oiseaux par rapport à l'homme, Marcy Norton utilise des traités de fauconnerie espagnols, des récits de voyages ou des représentations des Amérindiens. Giorgio Riello réévalue l'intérêt des inventaires pour analyser la consommation. Produit des conventions sociales et juridiques, l'inventaire est statique et fixé dans le temps. Or, les produits se modifient physiquement dans le temps, tout comme la valeur qui leur est assignée (p. 127 et 144). Rapidement, le lecteur comprend qu'il faut activer les objets et les replacer dans les expériences quotidiennes ; en bref, il faut les recharger de leur vie - oubliée jusqu'ici malgré les appels de Fernand Braudel et Arjun Appadurai.

3 La première partie de l'ouvrage insiste sur l'ambiguïté des choses et en particulier sur leur instabilité. Carla Nappi explique la difficulté d'une biographie du ginseng en Chine. Espèce végétale stable, son identité et son sens évoluent au fil du temps selon des contextes historiques, géographiques et philosophiques variables (p. 45-46). Jessika Riskin montre le parallèle établi entre horlogerie, cosmos, animal et corps humain à partir d'une vision des «flux corporels » liée à l'agitation. Or, depuis cette époque, l'horloge est devenue un symbole de régularité et de précision (p. 84 et 97).

4 Dans une seconde section, les mécanismes de représentations visuelles ou écrites des objets sont mis au jour. Les natures mortes hollandaises sont présentées comme des invitations à prendre conscience de soi face à une vision de la matérialité au XVII siècle. Selon Julie Hochstrasser, les mêmes natures mortes interrogent le «moi» du spectateur à cinq siècles de distance. Giorgio Riello insiste sur la subjectivité des inventaires domestiques. Ils deviennent alors les images d'un instant « $\mathrm{T}$ » révélant les intentions des compilateurs. Les inventaires sont alors des morceaux de pensée plus que de réalité (p. 125-127 et 144). À partir d'un livre de voyage français du XvI $\mathrm{e}^{\mathrm{e}}$ siècle et de l'analyse des vêtements ottomans, Chandra Mukerji montre le rapprochement entre culture européenne et culture ottomane.

Dans la troisième section portant sur la fabrication, Pamela Smith démontre que l'écriture d'un traité de techniques $\mathrm{du} \mathrm{XVI}^{\mathrm{e}}$ siècle se réalise sous un mode créatif. La description des actions entre en symbiose avec l'acte d'écrire. La fabrication est à la fois plastique (coulée du métal) et intellectuelle (rédaction des étapes techniques). C'est par la reconstruction - voire la reconstitution - que Smith met au jour l'effort de créativité du rédacteur. Corey Tazzara étudie les journaux et inventaires d'artisans florentins du $\mathrm{XVII}^{\mathrm{e}}$ siècle, comme les vitriers, afin de montrer le fil des transformations de la matière première aux produits finis.

6 Dans «L'empire des choses », Erika Monahan montre la trajectoire de la rhubarbe, racine négligée devenu produit médicinal précieux (p.244-245). Du désintérêt à 
l'enthousiasme, elle présente les modifications de la valeur d'une plante. Mark A. Peterson s'intéresse aux liens entre la politique économique dans le monde atlantique et les pièces d'argent. Il met ainsi en valeur une transformation matérielle et politique de l'argent espagnol jusqu'au shilling de la Nouvelle Angleterre, preuve de la réussite de la politique économique du Massachusetts (p. 268-270). Alan Mikhail examine le trajet d'un bois d'Anatolie, devenu coque de navire à Suez pour finalement transporter du grain en Arabie Saoudite. Le bois et le grain participent au façonnage de l'histoire de l'empire ottoman (p. 285-286 et 366).

7 Le chapitre sur la consommation a pour ambition d'explorer les objets consommés comme indicateurs d'identité des personnes qui les possèdent et les utilisent. Morgan Pitelka étudie trois objets de l'entrepôt Tokugawa, un bol de thé bleu et blanc, une épée et une arquebuse (p. 297). Les deux derniers sont associés à la guerre, tandis que le thé est un élément de la civilité masculine des hommes japonais. Les trois objets peuvent être instrumentalisés politiquement, en faisant l'objet d'échanges afin de renforcer ces relations. Ce chapitre trouve parfaitement sa place à côté de celui d'Amanda Vickery. Elle examine la construction de la féminité et de la masculinité à partir de la création et de la commercialisation de meubles « solides et délicats » dans l'Angleterre géorgienne (p. 342).

8 Le dernier chapitre, «Le pouvoir des choses", discute des contributions des auteurs. Les objets peuvent être saisis dans leur mobilité, créant ainsi des flux de choses, ou comme marqueurs d'une identité genrée, ou encore construction d'un imaginaire ou d'une pensée.

Il faut recommander cette lecture aux étudiants et aux chercheurs qui s'intéresseraient à une approche multidisciplinaire et connectée. Cet ouvrage stimulant ouvre de nombreuses perspectives portant sur la culture matérielle. Parmi les orientations possibles, j'insisterais sur une approche sensorielle et émotionnelle des objets située au carrefour d'une recherche complexe relevant à la fois des sciences et des techniques, du politique et de l'histoire économique et sociale. Cet ouvrage prouve que ce type d'histoire totale, ou d'histoire profonde pénétrant les débuts du matériau au façonnage, statiques et mobiles à la fois, sans omettre d'intégrer les acteurs sociaux, économiques et politiques qui s'y intéressent, est envisageable lorsque les sources, la géographie et l'engagement des acteurs sont pleinement considérés. Après L'œil écoute de Paul Claudel (1946) et Ce que sait la main de Richard Sennett (2008), à quand « Le souffle des objets »?

\section{AUTEURS}

\section{AUDREY MILLET}

European University Institute 